\title{
Polymorphism of CYP46A1 Gene and Alzheimer's Disease in the Iranian Population
}

\author{
Rohollah Mousavidehmordi, ${ }^{1}$ Hossain Babaahmadi, ${ }^{1}$ Bita Shalbafan, ${ }^{2}$ Ghorban Mohammadzadeh, ${ }^{1}$ \\ Mohammadreza Afsharmanesh, ${ }^{1}$ and Alireza Kheirollah,", \\ ${ }^{1}$ Department of Biochemistry, Medical School, Cellular \& Molecular Research Center, Ahvaz Jundishapur University of Medical Sciences, Ahvaz, IR Iran \\ ${ }^{2}$ Department of Neurology, Medical School, Jundishapur University of Medical Sciences, Ahvaz, IR Iran \\ "Corresponding author: Alireza Kheirollah, Department of Biochemistry, Medical School, Cellular \& Molecular Research Center, Ahvaz Jundishapur University of Medical \\ Sciences, Ahvaz, IR Iran. Tel: +98-9167505075, Fax: +98-6133738632, E-mail: akheirollah@gmail.com
}

Received 2016 August 02; Revised 2016 September 08; Accepted 2016 September 17.

\begin{abstract}
Background: Cholesterol homeostasis in the brain has been demonstrated in the pathogenesis of Alzheimer's disease (AD). Experimental data support that brain cholesterol turnover can modulate central processes in AD pathogenesis. Excess cholesterol is eliminated from the brain via hydroxylation mediated by cholesterol 24S-hydroxylase (CYP46A1), a main mechanism of maintaining cholesterol homeostasis. The CYP46A1 gene has been suggested as a genetic risk factor for AD.

Methods: In this case-control study, we analyzed an intronic CYP46A1 gene single-nucleotide polymorphism (SNP) in $100 \mathrm{AD}$ patients and 80 age- and sex-matched control subjects in the Iranian population.

Results: We found a significant difference in CYP46A1 TT-homozygotes genotype $\left(\chi^{2}=5.06, \mathrm{df}=1, \mathrm{P}=0.02\right)$ and T allele frequency $\left(\chi^{2}=6.09, \mathrm{df}=1, \mathrm{P}=0.01\right)$ between $\mathrm{AD}$ patients and controls.

Conclusions: The results of our study indicate that intron T/C polymorphism of the CYP46A1 gene is associated with $\mathrm{AD}$ in the Iranian population, and that the CYP46A1 TT genotype or T allele frequency might be a genetic risk factor for $\mathrm{AD}$ and increase susceptibility to AD.
\end{abstract}

Keywords: Alzheimer's Disease, CYP46A1 Gene, Single-Nucleotide Polymorphism, Brain Cholesterol Homeostasis

\section{Background}

Alzheimer's disease (AD) is a progressive neurodegenerative disorder and the most common cause of dementia that affects memory and cognitive function. It is characterized by intracellular neurofibrillary tangles that consist of hyper phosphorylated twisted filaments of the microtubule-associated protein tau and extracellular senile plaques that comprise $\beta$-amyloid peptide ( 1 , 2 ). Variability of cholesterol metabolism and distribution in the brain has been demonstrated in the pathogenesis of $\mathrm{AD}$, and experimental data support that brain cholesterol turnover can modulate central processes AD pathogenesis (3). Homeostasis of brain cholesterol is very stable compared to the cholesterol of the periphery. Cholesterol is mainly synthesized locally in the brain, as its transfer is restricted by the blood-brain barrier (4). Therefore, homeostasis of cholesterol in the brain occurs via catabolized of excess cholesterol into 24S-hydroxcholesterol (24OHC), which is catalyzed by cholesterol 24S-hydroxylase enzymes (CYP46A1; Cytochrome P450, family 46, subfamily
A, polypeptide 1) and then secreted from the central nervous system into the plasma across the blood-brain barrier (5). Also termed an oxysterol, $24 \mathrm{OHC}$ is the major removal metabolite of the brain cholesterol. As high levels of neurotoxic $24 \mathrm{OHC}$ may contribute to advanced neurodegeneration, it is considered a genetic risk factor for $\mathrm{AD}(6)$.

It also is believed that an increased or decreased concentration of $24 \mathrm{OHC}$ metabolite in the brain may favor the development of $\mathrm{AD}$ by accelerating the accumulation of beta-amyloid and promoting neuronal death (7). The CYP46A1 gene is 42,985 bases long and resides on human chromosome 14 q32.1. This gene encodes cholesterol 24hydroxylase, a member of the cytochrome P-450 superfamily, and converts cholesterol to $24 \mathrm{OHC}$. Cholesterol 24-hydroxylase is expressed in the brain, where it regulates the elimination of excess cholesterol $(8,9)$. Genetic variants of several genes are involved in the etiology of AD. Polymorphism in the presenilin-1 (PSEN1), presenilin2 (PSEN2), and amyloid precursor protein (APP) genes has been identified as a primary contributor in familial autosomal-dominant $\mathrm{AD}(10)$; however, familial $\mathrm{AD}$ is re- 
sponsible for just 2\% of total Alzheimer's patients (11). The majority of Alzheimer's patients manifest with sporadic late-onset $A D(L O A D)$, which appears after age 65. In recent decades, several candidate genes have been associated with LOAD. Among these, the ApoE4 allele of Apo lipoprotein $\mathrm{E}$ gene has been recognized as the only demonstrated genetic risk factor for LOAD (12).

Several studies indicate that polymorphisms in the CYP46A1 gene influence beta-amyloid peptide load in the brain and that susceptibility of this polymorphism with the risk of $\mathrm{AD}(6,13)$. In addition, polymorphism $(\mathrm{T} / \mathrm{C}$, rs754203) in the CYP46A1 gene is associated with an increased risk for $\mathrm{AD}$ along with increased beta-amyloid load in brain tissues and with increased cerebrospinal fluid levels of beta-amyloid peptides and phosphorylated tau protein was reported (14). In studies of the relationship between CYP46A1 gene polymorphism and AD risk, a single nucleotide polymorphism (SNP) T/C in the region rs754203 of the CYP46A1 gene has been identified, and a significant correlation with an increased risk for AD has been revealed. According to these studies, the frequency of both the CYP46A1 TT-homozygotes genotype and the T allele was significantly higher in AD patients than in controls (15-17). Conversely, other studies reported that the CChomozygotes genotype was observed more frequently in $\mathrm{AD}$ patients than in the control subjects (18-20). Other, similar studies failed to show any significant association between CYP46A1 gene polymorphism and AD risk $(21,22)$.

\section{Objectives}

In this study, therefore, we investigated the association between polymorphism T/C in the region rs754203 of the CYP46A1 gene and $A D$ in the Iranian population.

\section{Methods}

A total of $100 \mathrm{AD}$ patients (mean age $=72.7$ years, $\mathrm{SD}=$ 10.5 , range $=51-94$ ) and 80 controls (mean age $=71.1$ years, $\mathrm{SD}=6.4$, range $=65$ - 91) were recruited from outpatient clinics of several medical centers. The diagnosis of AD patients by neurological physicians was based on criteria in the diagnostic and statistical Manual of mental disorders (DSM-IV), a manual published by the American psychiatric association (APA) that includes all currently recognized mental health disorders, and supported by neurological examination, neuroimaging data including computed tomography (CT) or magnetic resonance imaging (MRI), and cognitive function tests, including mini-mental state examination(MMSE). Control subjects were selected through evaluation of medical history and neurological examination. Neurological physicians performed MMSE to assess the cognitive function in control subjects. All control subjects had MMSE scores of $\geq 26$. All subjects were Iranian, originating from three limited geographical areas: in the capital of Khuzestan, Fars, and Isfahan provinces. Informed consent to participate in the study was obtained from all subjects, either directly or via guardians.

The study protocol was approved by the ethics committee of the Ahvaz Jundishapur University of Medical Sciences, Iran. Genomic DNA was isolated from whole blood samples using the QIAamp blood kit (QIAGEN, Hilden, Germany). A 632 base pairs (bp) polymerase chain reaction (PCR) product containing the CYP46A1 gene SNP was amplified using the forward primer $5^{\prime}$. TCCTCCTACCTTAACCGACTCAG- $3^{\prime}$ and reverse primer $5^{\prime}$ GACTCCCAGCCTCACCTTCC-3' ${ }^{\prime}$ Amplification primers were designed by Alell ID software. PCR was performed using 1 $\mu \mathrm{g}$ of genomic DNA in $25 \mu \mathrm{L}$ of reaction mixture consisting of $0.2 \mu \mathrm{M}$ of each primer, $12.5 \mu \mathrm{L}$ master mix PCR(Taq DNA Polymerase 2x Master Mix RED; Ampliqon, Denmark). After initial denaturation at $95^{\circ} \mathrm{C}$ for 5 minutes, the reaction conditions were subjected to 35 cycles of 30 seconds ECONDS denaturation at $95^{\circ} \mathrm{C}, 30$ seconds annealing at $56^{\circ} \mathrm{C}$, and 60 seconds extension at $72^{\circ} \mathrm{C}$, followed by a final 5 minutes extension step at $72^{\circ} \mathrm{C}$.

Analysis

All statistical analyses were performed with the statistical package for social sciences (SPSS) software. Allelic frequencies were estimated by the allele counting method. Comparison of genotype and allelic frequencies between $\mathrm{AD}$ patients and controls was analyzed by Pearson $\chi^{2}$ tests. The Hardy-Weinberg equilibrium was performed with the Gene pop software (the exact HW test) for both populations. Statistical significance was assumed at $\mathrm{P}<0.05$.

\section{Results}

Table 1 shows the frequency of men and women, the mean age at the time of the study, and MMSE scores in the $180 \mathrm{AD}$ patients and control subjects recruited for this study. All control subjects were matched well to AD patients by sex and age. No significant differences in the mean age $(P=0.35)$ and sex $(P=0.65)$ were observed between the patients and the control subjects. The distribution of CYP46A1 genotypes followed the Hardy-Weinberg equilibrium among AD patients and control subjects. All control subjects had MMSE scores of $\geq 26$.

Genotyping of the CYP46A1 SNP was performed by digesting the PCR product with the Fast Digest MspI restriction enzyme (Thermo Scientific or Fermentas, Germany). The CYP46A1 T allele corresponded to the uncut $632 \mathrm{bp}$ product, while the CYP46A1 C allele was recognized by two 
Table 1. Frequency of Sex Distribution, the Mean Age, and MMSE Scores in AD Patients and Controls

\begin{tabular}{|c|c|c|c|c|c|c|}
\hline \multirow[t]{2}{*}{ Subjects } & \multirow[t]{2}{*}{ Number } & \multicolumn{2}{|c|}{ Gender } & \multirow[t]{2}{*}{ Mean age } & \multirow[t]{2}{*}{ Range } & \multirow[t]{2}{*}{ MMSE } \\
\hline & & Male & Female & & & \\
\hline AD patients & 100 & 38 & 62 & 72.7 years & 51 - 94 years & Variable \\
\hline Controls & 80 & 33 & 47 & 71.1 years & 65 - 91 years & $26 \leq \mathrm{MMSE}$ \\
\hline Total & 180 & 71 & 109 & & & \\
\hline
\end{tabular}

fragments of 392 and $240 \mathrm{bp}$. These fragments were migrated on a $1 \%$ agarose gel (Cinnagen, Iran) stained with DNA-safe stain (Cinnagen, Iran) and visualized under ultraviolet light. Distribution of the CYP46A1 genotypes and allele frequencies in AD patients and control subjects, when $\mathrm{AD}$ and control groups were stratified by sex, is shown in Table 2 . The results of our study indicated that the distribution of CYP46A1 TT-homozygotes genotypes was significantly different in AD patients and controls in female subsets when $\mathrm{AD}$ and control groups were stratified by $\operatorname{sex}\left(\chi^{2}\right.$ $=5.06, \mathrm{df}=1, \mathrm{P}=0.02$ ).

The CYP46A1 allele frequencies in Iranian AD patients were $25.0 \%$ for C allele and $75.0 \%$ for T allele. Significant differences were found between the distributions of CYP46A1 $\mathrm{T}$ allele in female subsets $\left(\chi^{2}=6.09, \mathrm{df}=1, \mathrm{P}=0.01\right)$ of $\mathrm{AD}$ patients and controls when stratified by sex. No significant difference in total distribution of the CYP46A1 genotypes and allele frequencies was observed between the cases when $\mathrm{AD}$ patients and control subjects were not stratified by sex (Table 2).

\section{Discussion}

DNA sequencing of the CYP46A1 gene revealed that each gene contained 14 introns and 15 exons. The mRNA of the CYP46A1 gene is mainly expressed in the gray matter of the brain. In studies of animals, abundant mRNA of the CYP46A1 gene was also found in neurons of the cerebral cortex, hippocampus, and thalamus (9). These brain structures are known to be preferentially affected in AD brains. An increasing number of studies have suggested that CYP46A1 gene polymorphism occurs in the development of AD. The majority of studies have focused on investigating the association of SNP (T/C) in the region rs754203 of the CYP46A1 gene with AD. However, these studies have shown contradictory or inconsistent results (23). According to these study reports, the volumes of parahippocampal and hippocampal gray matter in subjects with the TT-homozygotes genotype positive were smaller than in CC-homozygotes and CT-heterozygotes genotype subjects (24). In addition, previous studies showed that brain $\beta$ amyloid load and cerebrospinal fluid levels of phosphory- lated tau protein in AD patients with the CYP46A1 gene TThomozygotes genotype were significantly higher than in subjects without the TT-homozygotes genotype. Therefore, polymorphism of the CYP46A1 gene may be involved in the pathogenesis of $\mathrm{AD}$ by regulating $\beta$-amyloid generation indirectly (14).

The present study is the first to research the association analysis of polymorphism T/C in the region rs754203 of the CYP46A1 gene with AD in the Iranian population. Our study reports on the association of CYP46A1 gene polymorphism with AD risk in the Iranian population. In this casecontrol study, we observed that the distribution of CYP46A1 TT-homozygotes genotypes and T allele frequencies was significantly different in AD patients and controls. When AD patients and control subjects were not stratified by sex, no significant difference was observed in distribution of the CYP46A1 genotypes and allele frequencies. A possible, and more likely, reason may be that the smaller number of male subsets than female subsets in $\mathrm{AD}$ patients is responsible for the lack of association between TT-homozygotes genotypes and $\mathrm{T}$ allele status with increases in the risk of $\mathrm{AD}$ in male subsets.

According to the largest meta-analysis, consisting of $4,875 \mathrm{AD}$ patients and 4,874 control subjects from twentyone studies, the association between CYP46A1 gene T/C (rs754203) polymorphism and an increased risk of AD is both significant and correlated (23). Recently, the AlzGene database published a total of twenty-seven studies showing correlation between $\mathrm{T} / \mathrm{C}$ (rs754203) polymorphism and AD risk. According to this report, several of these studies have implicated that polymorphism of the CYP46A1 gene is associated with the risk of $\mathrm{AD}$ (AlzGene; www.alzgene.org). Nevertheless, the results were inconsistent among the positive studies. For example, TT-homozygotes genotype and $\mathrm{T}$ allele frequency was reported as posing a higher risk of $\mathrm{AD}$ in two Caucasian and Chinese populations $(14,15)$. However, according to the outcomes of other studies, CChomozygotes genotype was higher in $\mathrm{AD}$ patients than in control subjects $(25,26)$. Most likely, the disagreements between the studies could be correlated to the ethnic variability in different populations or methodological differences. These results also could mean that the susceptibility 
Table 2. CYP46A1 Genotype Distribution and Allele Frequencies in AD Patients and Control Groups, Stratified by Sex in Male and Female Subsets ${ }^{\mathrm{a}}$

\begin{tabular}{|c|c|c|c|c|c|c|c|c|c|}
\hline \multirow[t]{2}{*}{ Genotype and Allele Frequency } & \multicolumn{2}{|c|}{ Total } & \multirow[t]{2}{*}{$\mathbf{P}$} & \multicolumn{2}{|c|}{ Male } & \multirow[t]{2}{*}{$\mathbf{P}$} & \multicolumn{2}{|c|}{ Female } & \multirow[t]{2}{*}{$\mathbf{P}$} \\
\hline & Patients & Controls & & Patients & Controls & & Patients & Controls & \\
\hline Tr-homozygote & 56 & 42 & 0.15 & 15 & 19 & 0.49 & 41 & 23 & 0.02 \\
\hline TC-heterozygote & 38 & 35 & 0.72 & 20 & 13 & 0.22 & 18 & 22 & 0.52 \\
\hline CC-homozygote & 6 & 3 & 0.31 & 3 & 1 & 0.31 & 3 & 2 & 0.65 \\
\hline T-Allele & 150 & 119 & 0.05 & 50 & 51 & 0.92 & 100 & 68 & 0.01 \\
\hline C-Allele & 50 & 41 & 0.34 & 26 & 15 & 0.08 & 24 & 26 & 0.77 \\
\hline
\end{tabular}

of polymorphism with the risk of AD may vary in different ethnic populations.

In conclusion, the results of our study indicate that intron polymorphism $\mathrm{T} / \mathrm{C}$ in the region rs754203 of the CYP46A1 gene is associated with AD in the Iranian population, and that CYP46A1 TT genotype or T allele frequency might be a genetic risk factor for AD and increase the susceptibility to AD in the Iranian population. Polymorphism $\mathrm{T} / \mathrm{C}$ in the region rs754203 of the CYP46A1 gene is not the only polymorphism in this gene; other polymorphisms in CYP46A1 gene but also may increase the risk for AD (4, 18). Synergistic interaction may exist between the polymorphism of the CYP46A1 gene and other genes involved in the cholesterol metabolism, such as the ApoE4 allele of Apo lipoprotein E gene $(15,20)$. Therefore, further studies investigating the effects of CYP46A1 gene polymorphism on homeostasis of cholesterol in the brain are needed in the future to confirm the substantial role of this gene in the pathogenesis of AD.

\section{Footnote}

Funding/Support: This work was financially supported by grant (873-A) from vice chancellor for research affairs of Ahvaz Jundishapur University of Medical Sciences.

\section{References}

1. Buee L, Bussiere T, Buee-Scherrer V, Delacourte A, Hof PR. Tau protein isoforms, phosphorylation and role in neurodegenerative disorders. Brain Res Brain Res Rev. 2000;33(1):95-130. [PubMed: 10967355].

2. Gendron TF, Petrucelli L. The role of tau in neurodegeneration. Mol Neurodegener. 2009;4:13. doi: 10.1186/1750-1326-4-13. [PubMed: 19284597].

3. Kirsch C, Eckert GP, Koudinov AR, Muller WE. Brain cholesterol, statins and Alzheimer's Disease. Pharmacopsychiatry. 2003;36 Suppl 2:S113-9. doi: 10.1055/s-2003-43058. [PubMed: 14574624].

4. Ma SL, Tang NL, Lam LC, Chiu HF. Polymorphisms of the cholesterol 24-hydroxylase (CYP46A1) gene and the risk of Alzheimer's disease in a Chinese population. Int Psychogeriatr. 2006;18(1):37-45. doi: 10.1017/S1041610205003108. [PubMed: 16734927].
5. Tedde A, Rotondi M, Cellini E, Bagnoli S, Muratore L, Nacmias B. Lack of association between the CYP46 gene polymorphism and Italian lateonset sporadic Alzheimer's disease. Neurobiol Aging. 2006;27(5):1-3.

6. Kolsch H, Lutjohann D, von Bergmann K, Heun R. The role of 24S-hydroxycholesterol in Alzheimer's disease. J Nutr Health Aging. 2003;7(1):37-41. [PubMed: 12679839].

7. Kolsch H, Lutjohann D, Tulke A. the neurotoxic effect of 24hydroxycholesterol on SH-SY5Y human neuroblastoma cells. Brain Res. 1999;818(1):171-5. doi:10.1016/S0006-8993(98)01274-8.

8. Bjorkhem I, Lutjohann D, Diczfalusy U, Stahle L, Ahlborg G, Wahren J. Cholesterol homeostasis in human brain: turnover of $24 \mathrm{~S}$ hydroxycholesterol and evidence for a cerebral origin of most of this oxysterol in the circulation.J Lipid Res. 1998;39(8):1594-600. [PubMed: 9717719].

9. Lund EG, Guileyardo JM, Russell DW. cDNA cloning of cholesterol 24hydroxylase, a mediator of cholesterol homeostasis in the brain. Proc Natl Acad Sci U S A. 1999;96(13):7238-43. [PubMed: 10377398].

10. Campion D, Dumanchin C, Hannequin D, Dubois B, Belliard S, Puel M, et al. Early-onset autosomal dominant Alzheimer disease: prevalence, genetic heterogeneity, and mutation spectrum. Am J Hum Genet. 1999;65(3):664-70. doi: 10.1086/302553. [PubMed: 10441572].

11. Huang Y, Weisgraber KH, Mucke L, Mahley RW. Apolipoprotein E: diversity of cellular origins, structural and biophysical properties, and effects in Alzheimer's disease. J Mol Neurosci. 2004;23(3):189-204. doi: 10.1385/JMN:23:3:189. [PubMed: 15181247].

12. Bertram L. Alzheimer's disease genetics current status and future perspectives. Int Rev Neurobiol. 2009;84:167-84. doi: 10.1016/S00747742(09)00409-7. [PubMed: 19501718].

13. Wolozin B. Cyp46 (24S-cholesterol hydroxylase): a genetic risk factor for Alzheimer disease. Arch Neurol. 2003;60(1):16-8. [PubMed: 12533083].

14. Papassotiropoulos A, Streffer JR, Tsolaki M, Schmid S, Thal D, Nicosia $\mathrm{F}$, et al. Increased brain beta-amyloid load, phosphorylated tau, and risk of Alzheimer disease associated with an intronic CYP46 polymorphism. Arch Neurol. 2003;60(1):29-35. [PubMed:12533085].

15. Wang B, Zhang C, Zheng W, Lu Z, Zheng C, Yang Z, et al. Association between a $\mathrm{T} / \mathrm{C}$ polymorphism in intron 2 of cholesterol 24S-hydroxylase gene and Alzheimer's disease in Chinese. Neurosci Lett. 2004;369(2):104-7. doi: 10.1016/j.neulet.2004.07.020. [PubMed: 15450677].

16. Fernandez Del Pozo V, Alvarez Alvarez M, Fernandez Martinez M, Galdos Alcelay L, Gomez Busto F, Pena JA, et al. Polymorphism in the cholesterol 24S-hydroxylase gene (CYP46A1) associated with the APOEpsilon3 allele increases the risk of Alzheimer's disease and of mild cognitive impairment progressing to Alzheimer's disease. Dement Geriatr Cogn Disord. 2006;21(2):81-7. doi: 10.1159/000090215. [PubMed: 16340204]

17. He XM, Zhang ZX, Zhang JW, Zhou YT, Wu CB, Tang MN, et al. An in tronic CYP46A1 polymorphism is associated with Alzheimer disease in a Chinese Han population. J Mol Neurosci. 2012;47(3):514-8. doi: 10.1007/s12031-012-9778-5. [PubMed: 22528464]. 
18. Kolsch H, Lutjohann D, Ludwig M, Schulte A, Ptok U, Jessen F, et al. Polymorphism in the cholesterol 24S-hydroxylase gene is associated with Alzheimer's disease. Mol Psychiatry. 2002;7(8):899-902. doi: 10.1038/sj.mp.4001109. [PubMed: 12232784].

19. Combarros O, Infante J, Llorca J, Berciano J. Genetic association of CYP46 and risk for Alzheimer's disease. Dement Geriatr Cogn Disord. 2004;18(3-4):257-60. doi: 10.1159/000080025. [PubMed: 15286456].

20. Helisalmi S, Vepsalainen S, Koivisto AM, Mannermaa A, Iivonen $S$, Hiltunen $M$, et al. Association of CYP46 intron 2 polymorphism in Finnish Alzheimer's disease samples and a global scale summary. J Neurol Neurosurg Psychiatry. 2006;77(3):421-2. doi: 10.1136/jnnp.2005.071928. [PubMed: 16484661].

21. Juhasz A, Rimanoczy A, Boda K, Vincze G, Szlavik G, Zana M, et al. CYP46 $\mathrm{T} / \mathrm{C}$ polymorphism is not associated with Alzheimer's dementia in a population from Hungary. Neurochem Res. 2005;30(8):943-8. doi: 10.1007/s11064-005-5979-4. [PubMed:16258842].

22. Kolsch H, Lutjohann D, Jessen F, Popp J, Hentschel F, Kelemen $P$, et al. CYP46A1 variants influence Alzheimer's disease risk and brain cholesterol metabolism. Eur Psychiatry. 2009;24(3):183-90. doi: 10.1016/j.eurpsy.2008.12.005. [PubMed: 19286353].

23. Li L, Yin Z, Liu J, Li G, Wang Y, Yang J. CYP46A1 T/C polymorphism associated with the APOE $\varepsilon 4$ allele increases the risk of Alzheimer's disease. J Neurol, Neurosurg Psychiatr. 2013;260(7):1701-8. doi: 10.1007/s00415012-6690-4.

24. Hanggi J, Mondadori CR, Buchmann A, Henke K, Hock C. A CYP46 T/C SNP modulates parahippocampal and hippocampal morphology in young subjects. Neurobiol Aging. 2011;32(6):1023-32. doi: 10.1016/j.neurobiolaging.2009.07.001. [PubMed:19647891].

25. Borroni B, Archetti S, Agosti C, Akkawi N, Brambilla C, Caimi L, et al. Intronic CYP46 polymorphism along with ApoE genotype in sporadic Alzheimer Disease: from risk factors to disease modulators. Neurobiol Aging. 2004;25(6):747-51. doi: 10.1016/j.neurobiolaging.2003.08.004. [PubMed: 15165699].

26. Golanska E, Hulas-Bigoszewska K, Wojcik I, Rieske P, Styczynska M, Peplonska B, et al. CYP46: a risk factor for Alzheimer's disease or a coincidence?. Neurosci Lett. 2005;383(1-2):105-8. doi: 10.1016/j.neulet.2005.03.049. [PubMed:15936520]. 